\title{
Product innovation tool adoption behaviour in technology-based new ventures
}

\author{
Gerrit A. de Waal* \\ Swinburne University of Technology, P.O. Box 218, Victoria 3122, Australia. \\ E-mail: ddewaal@swin.edu.au

\section{Paul Knott} \\ University of Canterbury, Private Bag 4800, Christchurch 8140, New Zealand. \\ E-mail: paul.knott@canterbury.ac.nz \\ * Corresponding author
}

\begin{abstract}
Despite the attention it gives to innovation tools, the product innovation literature does not address the behavioural motivation behind practitioners' adoption of particular tools, or relate this to new venture development. This paper focuses on technology-based new ventures executing their first projects and presents insights into how their innovation tool adoption evolves over time. The paper synthesises case study findings into a hierarchy of tool adoption states encapsulating how new venture teams started with an exclusive focus on effectiveness, and over time progressively attended to problem solving, efficiency, and finally resource management. They often progressed to the next state only in response to costly mistakes and delays, whereas the experienced team in our comparison well-established firm operated within all four states from project initiation. Knowledge of this hierarchy of tool adoption states could help new venture teams to optimise the time they invest in product innovation tools.
\end{abstract}

Keywords: Product innovation; tool adoption behaviour; technology-based new ventures; new venture evolution; development states.

\section{Introduction}

Understanding the factors that influence product innovation effectiveness and efficiency has been of interest to researchers for many decades, for example the development process, innovation supportive organisation, the firm's external environment, post-launch marketing effort, and product innovation tools. While there is considerable consensus about how product innovation should be managed, this consensus leaves many areas of innovation management under-researched (Ledwith and O'Dwyer, 2008). One such area is the focus of this study, namely when (at what stage in the process) and why (circumstantial factors that drive behaviour) practitioners in technology-based new ventures adopt tools in support of their product innovation projects. For the purposes of the study, new ventures include independent start-ups, small firms that are new to product innovation, and autonomous spin-off ventures.

In the context of this paper, product innovation tools are defined as "any structured aids, managerial or technical in nature, used for structuring or influencing the management and effective execution of the product innovation process and associated activities" (de Waal and Knott, 2010, p. 253), thus including techniques and methods. Ample evidence suggests that increasing the use or uptake of appropriate tools during the product innovation process and using these tools more effectively can improve innovation performance (Cooper and Edgett, 2008; Maylor, 2001; McQuater, Scurr, Dale, and Hillman, 1995; Nijssen and Frambach, 2000; Nijssen and Lieshout, 1995). For example, it can reduce the prevalence and cost of failed product innovation projects (Cooper, 1994; Song, Souder, and Dyer, 1997). However, to date there has been limited research dedicated to unravelling the reasons why practitioners, in any type of firm, use product innovation tools. Furthermore, Thia, Chai, Bauly and Xin (2005) suggested that future tool research ought to cover a wider selection of companies including small private companies.

In addition, very little research has focused on how founding teams evolve during the first critical stages of a venture (Clarysse and Moray, 2004). In this paper, we adopt a new venture team perspective and present case study findings showing how the tool adoption behaviour of practitioners in such teams evolves over time. We conducted this research among four technology-based new ventures, with one established hightechnology firm for comparison. We synthesise the data from these case studies in a hierarchy of tool adoption states for technology-based new ventures. This offers a clearer understanding of the learning process during the 
maiden project of a new venture and illustrates the differences in progression through learning states between types of new venture.

\section{Theoretical background}

Although our focus is specifically on technology-based new ventures, we first review the general literature on product innovation tools (in larger, established firms) with a focus on when and why practitioners use tools in support of the innovation process and what influences them to adopt tools.

\section{When to use product innovation tools?}

This question relates to the stages in the product innovation process when innovation practitioners adopt different types of tool in support of their activity. As there are a multitude of product innovation tools available to practitioners, selecting the most appropriate one for a particular task becomes a difficult challenge. A number of scholars have attempted to order tools in ways to assist selection. Nijssen and Lieshout (1995), for example, classified what they regarded as the most popular tools into the four categories of idea generation, product optimisation, marketing-mix optimisation, and prediction. They based this categorisation on what they considered to be the four underlying problems of product innovation. Adams (2004), on the other hand, also used four, but different categories: market research, engineering \& design, technology, and team support. Expanding on the perspective approach of Adams, is the work of de Waal and Knott (2010) who suggested a 12-perspective product innovation process framework which they populated with tools that the scholarly literature often cites. Other categorisation attempts (Tidd, Bessant, and Pavitt, 2005, 2008a, 2008b) used no less than three categorisation schemes on different occasions (by stage of process, unknown logic, and by theme, respectively). However, as managers often apply tools successfully outside the context for which they were originally designed (Mahajan and Wind, 1992; Yeh, Yang, and Pai, 2008), any attempt at categorising tools would have its limitations. Appropriately, Brady, Rush, Hobday, Davies, Probert and Banerjee (1997, p. 419) commented that "there is no single or best way of classifying management tools" and "categorisations [to aid in tool selection] will depend on the task at hand". When selecting a tool or set of tools, Brown (1997) and Farrukh, Phaal and Probert (1999) advised practitioners to use ones that are simple in concept and use; flexible; not mechanistic or prescriptive; capable of integrating with other tools, processes and systems; result in quantifiable improvement; and support communication and buy-in. In reality, though, very few tools will exhibit all of these positive traits and it would be fruitless for users to search for tools whose application is free from unwanted effects (Knott, 2008). Similarly, Cooper and Kleinschmidt (1986) warned that despite their potential benefits, the mere use of tools cannot provide any guarantee of success.

In conclusion, conceptually derived tool categorisation schemes in the extant literature do serve a purpose in suggesting the types of tools that could potentially be used in product innovation projects, but lack an empirically derived base that guides and explains the chronological adoption of categories of tools during the life of a typical new product innovation project in a technology-based new venture.

\section{Why use product innovation tools?}

This question relates to the circumstantial factors that drive practitioners' behaviour in relation to adoption, interpretation and use of innovation support tools. At a very basic level, product innovation practitioners use tools for two reasons. The first is to help them become effective (Koen, Ajamian, Boyce, Clamen, Fisher, Fountoulakis, Johnson, Puri, and Seibert, 2002), achieving something that they would otherwise not be able to do. Without having developed an alpha prototype, for example, one would not be able to prove technical feasibility of an advanced technological concept. The second purpose of tools has to do with efficiency: “... (tools) hold the promise of faster, better, cheaper” (Thomke, 2006, p. 24). More advanced tools would allow one to complete a job faster and probably at less cost than with less-advanced tools. 'Computer-aided design', for example, would enable a design engineer to be much more efficient in doing the design of a product rather than using manual draughting tools. Some tools are indispensable in achieving certain outcomes (effectiveness), while others simply help achieve better results (efficiency).

Evidence from the literature details a number of more specific reasons why organisations adopt innovation tools (focusing on large established high-technology firms):

- Tools help identify problems and improve on or predict new product success (cited as first and second reasons by both Nijssen and Lieshout (1995) and Mahajan and Wind (1992); 
- Tools facilitate positive change and improvements (McQuater et al., 1995);

- Tools enhance a firm's product innovation efforts (Nijssen and Lieshout, 1995);

- Tools affect product performance enhancements such as time to market, product cost and product quality (Maylor, 2001);

- Tools can be used to improve management's decision quality at different stages of the product innovation process (Schelker, 1976);

- Firms that adopt product innovation tools do so to increase flexibility and efficiency, help to manage knowledge effectively, improve productivity and time-to-market, gather on-line marketing information, and facilitate teamwork, amongst other motivations (Hidalgo and Albors, 2008).

Based on these studies, we can classify the motivations that drive tool adoption into the three main categories of process, product and management, as detailed in Table 1.

Table 1. Main reasons why product innovation practitioners use tools

\begin{tabular}{llll}
\hline \multicolumn{1}{c}{ Product Innovation Process } & Product & Management \\
\hline \multicolumn{1}{c}{ Efficiency } & & \multicolumn{1}{c}{ Effectiveness } & \\
\hline Increase productivity & Identify and solve problems & Reduce product cost & Make quality decisions \\
Reduce time-to-market & Facilitate change (carry out & Ensure quality & Facilitate teamwork \\
Reduce project cost & activities) & Improve performance & Support communication \\
Eliminate redundant & Manage knowledge & & Predict success \\
processes & Research the market & & \\
& Manage information & & \\
\hline
\end{tabular}

None of the studies we could find focused on the product innovation practitioners themselves, or sought to establish any chronology or set of contingencies that would motivate practitioners to adopt one category of tool or another. Indeed, no prior study has used separate categories of tools that match different purposes, which limits existing understanding of the variety of motivations and purposes for tool adoption. This is limiting in the same way as stating that people use vehicles to transport cargo, instead of specifying the class, capacity and weight of vehicle.

The current study aims to close the gaps in the literature by identifying categories of tools that match specific steps in the progression of a new-venture development project. The needs and motivations of team members and the evolution of the venture in which the project takes place will influence these steps, and in turn the steps have the potential to impact on project and venture performance.

\section{What influences tool adoption?}

Tool adoption refers to decisions by a firm, or teams or individuals within it, to use a particular tool in its innovation process (Nijssen and Frambach, 2000). The literature reports several characteristics for which researchers have found links with tool adoption, all in the context of large organisations (see Table 2).

Table 2. Influences on tool adoption

\begin{tabular}{ll}
\hline Significant positive & The level of interdepartmental communication ${ }^{1}$ \\
relation & The number of stages in the NPD process ${ }^{1}$ \\
& The company's innovation/NPD strategy ${ }^{1}$ \\
& The firm's prior adoption of tools and techniques ${ }^{1}$ \\
& ${ }^{\dagger}$ Top-down management support ${ }^{2,3}$ \\
& ${ }^{*}$ Firm size ${ }^{3}$ \\
\hline Marginally significant & The number of departments involved in NPD $^{1}$ \\
positive relation & ${ }^{\dagger}$ The influence of top management \\
& ${ }^{1}$ \\
\hline No ideam size & \\
\hline
\end{tabular}




\begin{tabular}{l}
\hline $\begin{array}{l}\text { Possible/Undetermined } \\
\text { Type of development project (high versus low novelty) } \\
\text { Consumer versus industrial goods }{ }^{4} \\
\text { Industry/ type of products innovation process }{ }^{6}\end{array}$ \\
\hline Notes \\
1: (Nijssen and Frambach, 2000), research done on industrial companies \\
2: (Rigby, 2001b), research done on management tools \\
3: (Chai and Xin, 2006), only surveyed 8 tools \\
4: (Tidd and Bodley, 2002, p. 135), a survey of 50 projects in 25 large UK firms \\
5: (Nijssen and Lieshout, 1995), suggested that tool adoption will be influenced by nature \\
of markets \\
6: (Thia et al., 2005) \\
*†: Discrepancies
\end{tabular}

Although these studies have shown a number of key influences on tool adoption, they have focused mainly at the level of the firm. As a result, the influence of factors within teams has not been fully articulated, for example the effects of team composition, conduct and experience. There is also scope to clarify some discrepancies, namely the strength of the positive influence top management can have on tool adoption and the extent to which firm size influences tool adoption.

Firm demographics are one of the influences identified in Table 2. One aspect of this is the extent to which consumer versus industrial product development leads to different tool choices and the adoption of different numbers of tools. McGuire (1973) illustrated how the distinction between consumer and industrial products makes for different product innovation flows. In line with this idea, the interviews and focus groups Nijssen and Lieshout (1995) carried out led them to conclude that business-to-business companies conduct product innovation in a different way to those producing consumer goods. Another potential firm effect on the number and choice of tools adopted is the type of product innovation process (Thia et al., 2005). This effect does not seem to have been formally tested, although Adams' (2004) findings provide frequency distributions for types of process adoption among large firms.

All of the above influences on tool adoption relate to studies conducted among large firms, and hence remain untested in the start-up milieu. Some factors, such as interdepartmental communication and top-down management support, only bear relevance in the context of large firms, and therefore need not be considered in small-firm studies such as the current one. Others remain potentially relevant, and hence we report on the demographics of our case study firms in Table 4 and consider them in our analysis to the extent that our data permits.

\section{New venture development}

In technology based new ventures, the process of firm development is closely linked to activities centred on the conduct of the first innovation projects (Kazanjian, 1988). Hence it is important to consider and understand issues in early firm growth and how these potentially impact practitioners' tool adoption behaviour.

Historically, scholars have presented new venture development using life cycle and growth stage models. Despite the intuitive appeal of these models, a body of critique highlights critical limitations. They are conceptually rather than empirically based (Hanks, Watson, Jansen, and Chandler, 1993a) and arguably lack reliability, validity and explanatory power (Phelps, Adams, and Bessant, 2007). Their critics argue that instead of the "linear, unidirectional, sequenced and deterministic" approach in these traditional models (Phelps et al., 2007, p. 17), scholars need a framework that allows for developments in high technology new ventures that happen simultaneously or in any order (Hansen and Bird, 1997). In this context, Levie and Lichtenstein (2010, p. 336) concluded that stage models can "act as a barrier to advancement of research on the growth of entrepreneurial organisations.”

Instead of following the traditional growth stage approach, for this study we adopt the 'dominant problems' concept from Kazanjian (1988) and the concepts of 'learning states' (Phelps et al., 2007) and 'dynamic states' (Levie and Lichtenstein, 2010). Kazanjian’s framework identifies sequentially occurring and recognisable problem-clusters (so-called dominant problems) that define the states businesses must surpass to maintain growth, taking into account industry, technology and other situational variables as summarised in Table 3. Kazanjian (1988) developed this framework empirically with specific reference to technology-based new ventures, and it has subsequently been widely cited and refined (Almus and Nerlinger, 1999; Dodge and Robbins, 1992; Hanks, Watson, Jansen, and Chandler, 1993b; Kazanjian and Drazin, 1990). The concept that firms have dominant problems over certain times is consistent with the recognition by critics of the growth stage 
approach that "an element of stages theory that is empirically true is that businesses tend to operate in some definable states for some periods of time” (Levie and Lichtenstein, 2010, p. 330).

\title{
Table 3. Kazanjian's mapping of dominant problems
}

\begin{abstract}
Stage 1: Conception and development
Primary focus on the invention and development of a product or technology; Structure and formality non-existent with almost all activity focused on technical issues; Activities implicitly and informally organised; Problems include construction of product prototype and selling business idea to backers.
\end{abstract}

Stage 2: Commercialisation

Completing product development; Organisation largely resembles a product innovation team; Problems and competences are largely technical; Focus primarily on learning how to make the product work well and how to produce it beyond prototype; Communication is face to face.

Stage 3: Growth

Major problems are to produce, sell and distribute product in volume and to avoid being shaken out of the market; Difficulty in building an efficient and effective task system; Experience constant state of change; Growth of hierarchy and advent of functional specialisation and reporting mechanisms.

Stage 4: Stability

Major problems / challenges: to maintain growth momentum and market position; Stable, functional, characterised by bureaucratic principles, formal structure, standardised and formalised rules and procedures; Developing 2nd and 3rd generation products.

In our study, we also draw on the progression of learning states in new venture development proposed by Phelps et al.(2007). This presents four development states (rather than stages) starting with ignorance and progressing through a learning process to awareness, knowledge and implementation. Teams progress to a new state when they overcome challenges at 'tipping points' (Gladwell, 2000), which they are able to do if they have sufficient absorptive capacity to obtain and utilise new knowledge (Cohen and Levinthal, 1990), for example through network building, external experts, or internal actions. According to Clarysse and Morray (2004), in entrepreneurial situations the main source of this new knowledge is experiential learning rather than collective knowledge of the environment. The Phelps et al. (2007) model considers a broad set of independent problem areas in which growing firms pass through learning states and tipping points, namely people management, strategic orientation, formalised systems, new market entry, obtaining finance, and operational improvement. A helpful variant of the learning states model is the 'dynamic states' approach outlined by Levie and Lichtenstein (2010) for entrepreneurial ventures. This expands on the learning state concept by outlining each state as an open, complex, adaptive system that operates in disequilibrium conditions. This adaptive system may transition between states according to external dynamics and/or by the team and firm's internal capacity to change.

In this study, we sought to codify how the knowledge, behaviours and motivations of practitioners in new ventures evolve as they relate to innovation tool adoption. These issues have not been adequately explored in the above literature, since they fall between the main concerns of both innovation tools scholars and new venture development scholars. The primary research questions for the study were when (at what stage in the process) and why (circumstantial factors that drive behaviour) practitioners in technology-based new ventures adopt product innovation tools in support of their development projects.

\section{Research methodology}

\section{Research design}

To address our research questions, we needed to investigate in detail the conduct of the first projects in a variety of new ventures. This pointed to the multiple case study method using purposive sampling as advocated by Eisenhardt (1989) given the lack of strong supporting theory that applies directly to our research questions (Rahim and Baksh, 2003). This method helps to develop contextual understanding of the drivers and patterns of behaviour. Because of the small number of firms, it does not show systematically how these drivers and patterns might vary across a population of firms, or demonstrate an empirical relationship with performance.

We selected product innovation projects in five high-technology firms of different sizes and stages of development as set out in Table 4. We selected firms and projects so that we could compare similar and dissimilar pairs of cases as outlined by Eisenhardt (1989). We selected two fully new ventures that were independent start-up 
firms (A and D). We could compare these to two slightly more established ventures (firms B and C), and to a project in a large firm with well embedded processes (firm E). In addition, we could compare within types, by contrasting the two new start-ups of different sizes (A and D), and by comparing the recently established firm (B) with the spin-off venture influenced by a parent firm (C). Although there is no precise guideline to the number of cases to be included in case study research (Perry, 1998), our selection of five cases falls within observed norms for case research in product innovation (Rahim and Baksh, 2003). To aid comparison between cases, we restricted our cases to hardware projects completed by firms in the South Island of New Zealand.

Table 4. Basis for case selection and case characteristics

\begin{tabular}{lccccc}
\hline Venture / Company & $A$ & $B$ & $C$ & $D$ & $E$ \\
Venture type & $\begin{array}{c}\text { New start-up } \\
\text { firm }\end{array}$ & $\begin{array}{c}\text { Recently } \\
\text { established } \\
\text { firm }\end{array}$ & $\begin{array}{c}\text { Spin-off } \\
\text { business }\end{array}$ & $\begin{array}{c}\text { New start- } \\
\text { up firm }\end{array}$ & $\begin{array}{c}\text { Established } \\
\text { business }\end{array}$ \\
& Founding & First complete & Founding & Founding & Established \\
process
\end{tabular}

Ventures A to D were purposely formed to take a product idea to market. Venture C was tasked to develop and launch a new product, but since it was a subsidiary of a long-established parent company, it was strongly influenced by existing, established management practices. While venture B had already been in business for several years when they took on the development of their product, it was their first complete product innovation project, and hence the company was inexperienced in product innovation. Venture E is an established firm with many years of product innovation experience. The estimated development time for their product was 24 months.

\section{Data collection}

Our main source of data was semi-structured interviews conducted with members of the product innovation teams, which we recorded and transcribed for subsequent analysis. For triangulation purposes we also used other forms of case study data as depicted in Figure 1. The objective of the first two phases was to collect background information on the participating ventures and the projects under study. In the interview phase, we systematically used the research questions to guide participants in recalling and reflecting on circumstances and sequences of events regarding their use of innovation tools during the one to three year period of the chosen project, which was the maiden project for the venture in all cases except for the comparison firm E. We refrained from referring to stage-gate processes or stage-of-growth models to avoid biasing the responses. At the end of each interview, we progressed to reflective discussion of continued developments after product launch and during the initiation of subsequent projects. After each interview, we administered a short structured questionnaire that captured specific aspects of tool selection and user characteristics. Where necessary, we carried out repeat interviews to gather additional data to verify key observations or check a fact. 


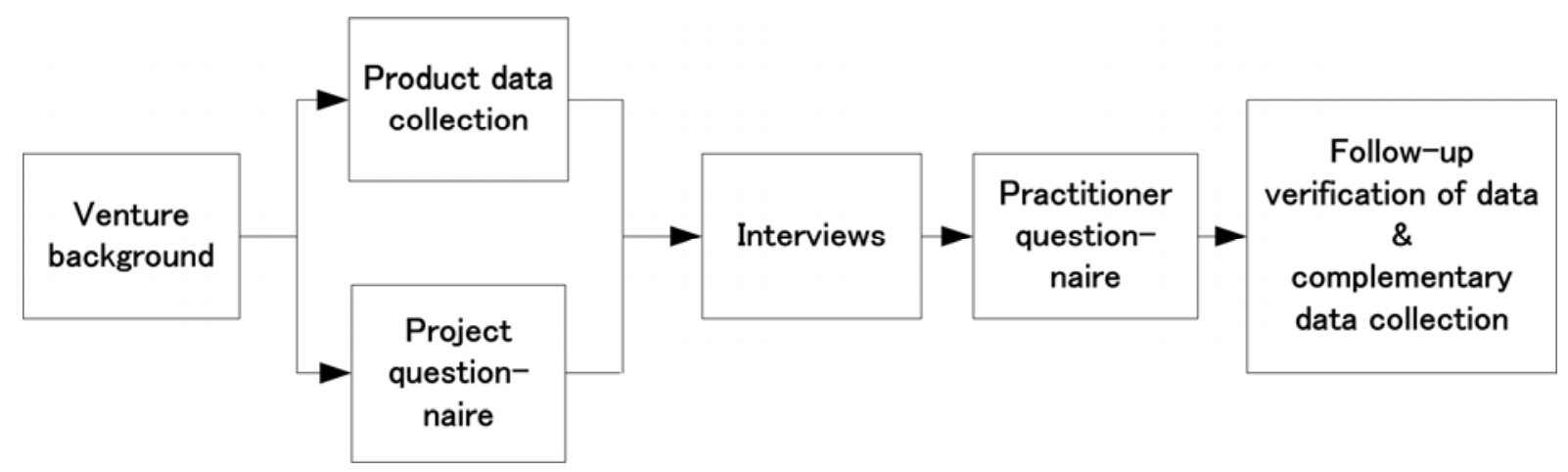

Fig. 1. Data collection chain of events

In the four ventures A-D, we interviewed three prominent team members who we selected to represent the breadth of discipline perspectives (e.g. project management, mechanical engineering, software development, marketing). Three interviews were sufficient for these ventures because of the small team size and the fact that each individual had multiple responsibilities during project execution. In company E, we conducted five interviews because the core development team was significantly larger than for the first four companies.

The interview data gave us an overview of the participants' motivation and behaviour with regard to adopting and incorporating tools into their product innovation activity at different stages in the development of their respective firms and projects.

\section{Results and analysis}

We started our analysis by compiling within-case summaries from the transcripts and by viewing both the raw transcripts and the summaries with the help of NVivo software. As we did so, we noted the following comment from Participant A3:

"Different product development tools become relevant at different stages of an organisation's development. For example, there are vast differences in a start-up developing a new, disruptive product and launching from scratch, to a well-established company with a portfolio of products that is looking towards implementing or improving their product development strategy."

In the remaining data, we saw that others described a similar evolution over time in the dominant challenges they faced and in their responses to these challenges. To represent this evolution, we grouped the data into four product innovation stages P1 to P4. Although these stages were partly inspired by the growth framework of Kazanjian (1988), our stages relate specifically to the time period and observations in our data: (1) concept development; (2) system design; (3) commercialisation; (4) portfolio review.

Appendix 1 presents some key passages from each company classified in the four stages. Below, we develop our interpretation of the data for each stage with respect to tool adoption behaviour. In the discussion section, we draw on the heterogeneity of our sample of firms to bring out other, non stage-related, differences in tool adoption behaviour.

\section{Product innovation stage P1: Concept development}

As new ventures launched their first product innovation projects, team members drew on a limited set of tools. These predominantly had a 'state-of-the-product' and market orientation. The reason for this narrow focus was that the firm or business unit was newly formed and participants described the period as chaotic, full of crises, lots of pressure on teams to perform, not enough time, tactical rather than strategic, and unstructured. In the new business units, this period was less disorganised, most likely due to the stabilising effect of the parent company. Due to the pressures they faced, team members tended to be pre-occupied with the physical product concept and how it evolves into a saleable product. Anything distracting them from 'getting the job done', such as using mission-non-critical tools, was pushed aside - "it can sit on the shelf until I need to use it” (Participant B1). Engineers and technicians invariably used tools such as 'CAD', 'prototyping' and other mostly technical tools because these are fundamental to the most immediate tasks. Similarly, the marketing people used the standard tools in a typical market research toolbox, such as 'needs analysis', 'voice of the customer', 'beta-testing' and 
'marketing plan'. We saw the same effect in other functional areas such as finance (focus on 'ROI', 'breakeven analysis') and manufacturing (focus on 'CIM', 'group technology'). Because team members cannot be effective without these tools, we coined the term 'effectiveness tools' to categorise tools used at this stage. Our participants were generally very familiar with the tools in this category, selected them almost automatically for a given task, and tended to use them in a very thorough manner.

\section{Product innovation stage P2: System design}

Teams often found it necessary during the system and detailed design stage of the project to adopt tools reactively in order to help solve unexpected problems or make difficult decisions. Labels they gave to tools adopted in this way included 'emergency', 'incidental', and 'problem solving' (e.g. 'brainstorming', 'focus groups', 'TRIZ', 'design of experiment'). Teams adapted tools as they saw fit to address the problem - "when problems arose, the team would resort to whatever tool was needed, off-the-shelf or custom made, to solve it" (Participant B2). Both novice (ventures A-D) and experienced (venture E) teams used tools in this way, but novice teams were less likely to anticipate problems in advance and hence less likely to use problem solving tools in a pro-active manner. Inexperienced teams also applied such tools only to the point of resolving the immediate problem, and then stopped - "we focus on solving immediate problems, nothing more, nothing less" (Participant C1). In contrast, in the more experienced team (venture E) this was not usual - "only about 5\% to $10 \%$ of tools used during the project were newly adopted because of situations where we suddenly realised we haven’t got any tools for a particular problem” (Participant E1).

\section{Product innovation stage P3: Commercialisation}

After stages P1 and P2, roughly 12 to 18 months after start-up, novice teams realised that there is more to product development than just the product and its customers. The projects became more complex, more people became involved, managing them became more cumbersome, and costs could blow out. In response, teams became more disciplined and developed procedures for groups of activities, and those firms with NPD processes in place gave them more attention. In terms of product innovation tools, team members started to realise the importance of tools that can eliminate repetitive processes, improve productivity, and help reduce time-tomarket and project cost - "we need to identify some good tools and we need to make use of them all so that the whole development process is more easily managed" (venture A). We refer to this category of tools as 'efficiency tools'. The use of this type of tool became internalised in the culture such that they became part of "the way we do things around here” (venture E). Tools in the efficiency category include 'workflow', 'Intranet', 'engineering document management system', 'bug tracking', 'project management', 'enterprise resource planning', 'product innovation process', 'stage gates', and 'checklists'.

\section{Product innovation stage P4: Portfolio review}

Eventually, after having completed two or more projects, the innovation teams became more experienced and the task environment became more stable. At this stage, they were in a position to review projects and view them as a portfolio. We noticed that team members used some tools pro-actively for their potential benefits, even when the tools were not immediately critical to achieving a saleable product that met target specifications. Rather, the tools were aimed at optimising the use of resources (such as project team or extended project team members, collaboration partners, suppliers, customers, tacit and explicit knowledge). Tools in this category included 'knowledge management', 'cross-functional teams', 'post launch review', 'post-project review', 'customer satisfaction tracking', 'teambuilding' and 'team launch systems'. These tools help in the sharing and transferring of knowledge between different groups and across projects, and hence embody a 'big picture' perspective that goes beyond the current project.

Only one of the four new-venture teams in our study (venture C) described using this type of tool during their first project, even they used them only to a limited degree. By comparison, big-picture tools were well-embedded in the established venture E, which stood out from the first four cases in this respect. Internal critique pointed instead to a need for renewal and re-focusing. Existing processes were well-embedded, but had not been updated for some years and were not well suited to the scope and magnitude of current projects. In addition, according to one participant (Participant E1), some team members still resisted buy-in to certain practices and tools.

\section{Synthesis: hierarchy of tool adoption states}


We now consider our extracted descriptions in Appendix 1 and our interpretations above in relation to the new venture development literature, and hence propose a model that encapsulates our findings. The teams' interpretations of the context, their motivations and tool adoption behaviour strongly suggest to us a learning process similar to the series of tipping points and dynamic learning states outlined by Phelps et al. (2007) and Levie and Lichtenstein (2010). In this case, the learning states relate to the classes of support tool that teams adopt, which in turn is driven by their evolving perception of priorities. Although we see the priorities evolving with product innovation stage and firm development, this evolution does not involve abandoning earlier learning but instead builds on it progressively. Hence, in Figure 2 we represent our conceptual model as a hierarchy, in which teams move up through progressively higher states in a way that is similar in principle to Maslow's (1943) hierarchy of human needs. Thus, teams do not abandon previously adopted tools as they move to a higher tool adoption state. Although our model draws on the dynamic learning states concept from Phelps et al. (2007) and Levie and Lichtenstein (2010), the states are different, as our study is specific to product innovation tool adoption during the start-up period of a new venture.

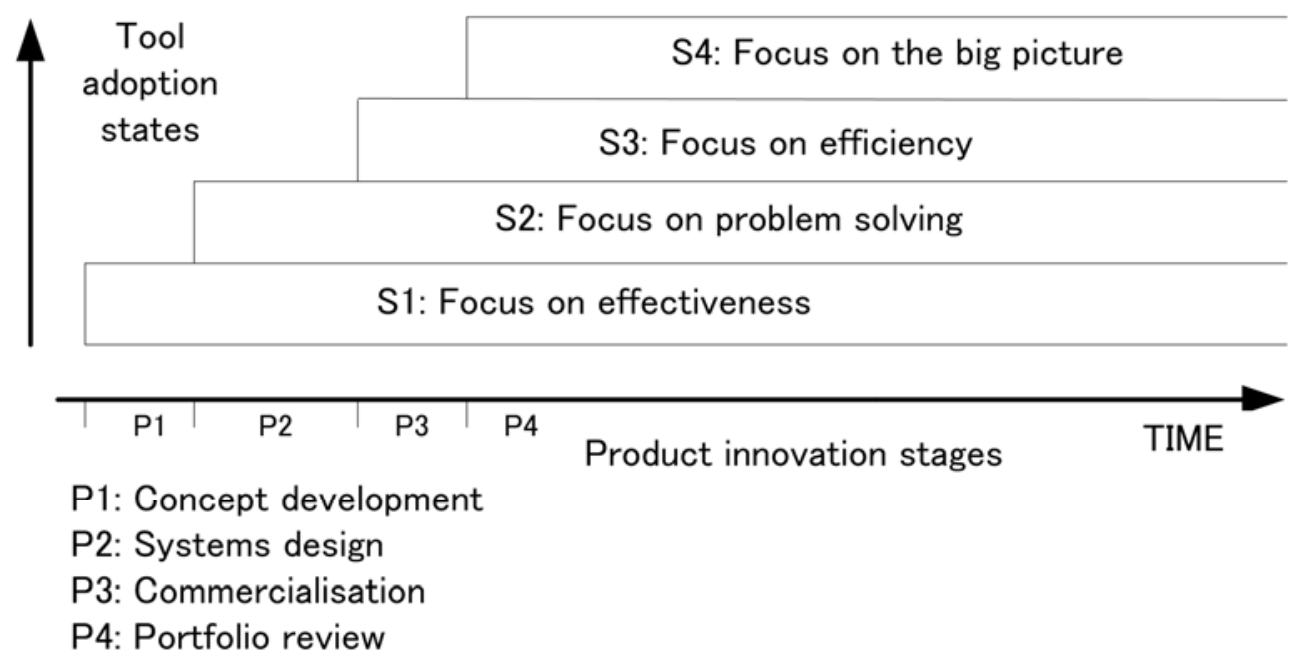

Fig. 2. Hierarchy of tool adoption states in technology-based new ventures

In our suggested model, as new venture teams progress through the four product innovation stages P1 - P4, the dominant problems that they perceive also evolve. At the concept development stage, time and resources are scarce and teams focus narrowly on immediate effectiveness (S1). They adopt tools with a state-of-the-product and market orientation, and no others. As they enter the system design stage (which includes detail design), engagement with the full complexity of the design process generates new and unanticipated problems. These trigger teams to progress to a new tool adoption state (S2) in which they start to adopt tools oriented to problem solving. Later, as they grapple with on-going orders, production, and increased commercial complexity in what we term the commercialisation stage, they progress to a third tool adoption state (S3) in which they implement tools with a process orientation that address efficiency. Finally, when firms move beyond an individual project, they need greater sophistication in managing the firm's innovation resources and in managing priorities across a portfolio of projects. In response, they adopt 'big picture' tools (S4), for example those focused on resource management. This progression in learning states represents tool adoption behaviour as we observed it in our case study ventures, and not a theoretical optimum.

An important aspect of our proposed hierarchy of tool adoption states is that moving to higher states represents a learning process in response to triggers or tipping points. Teams might not progress through all states, either because they do not reach all tipping points or because they lack the capacity to respond. In Figure 3 , we portray schematically the progression of tool adoption states in each of the five case study companies. The progression relates to the projects we studied, which were the maiden projects for each venture except in venture E. 


\section{Maiden project for ventures $A, B, C$ and $D$}
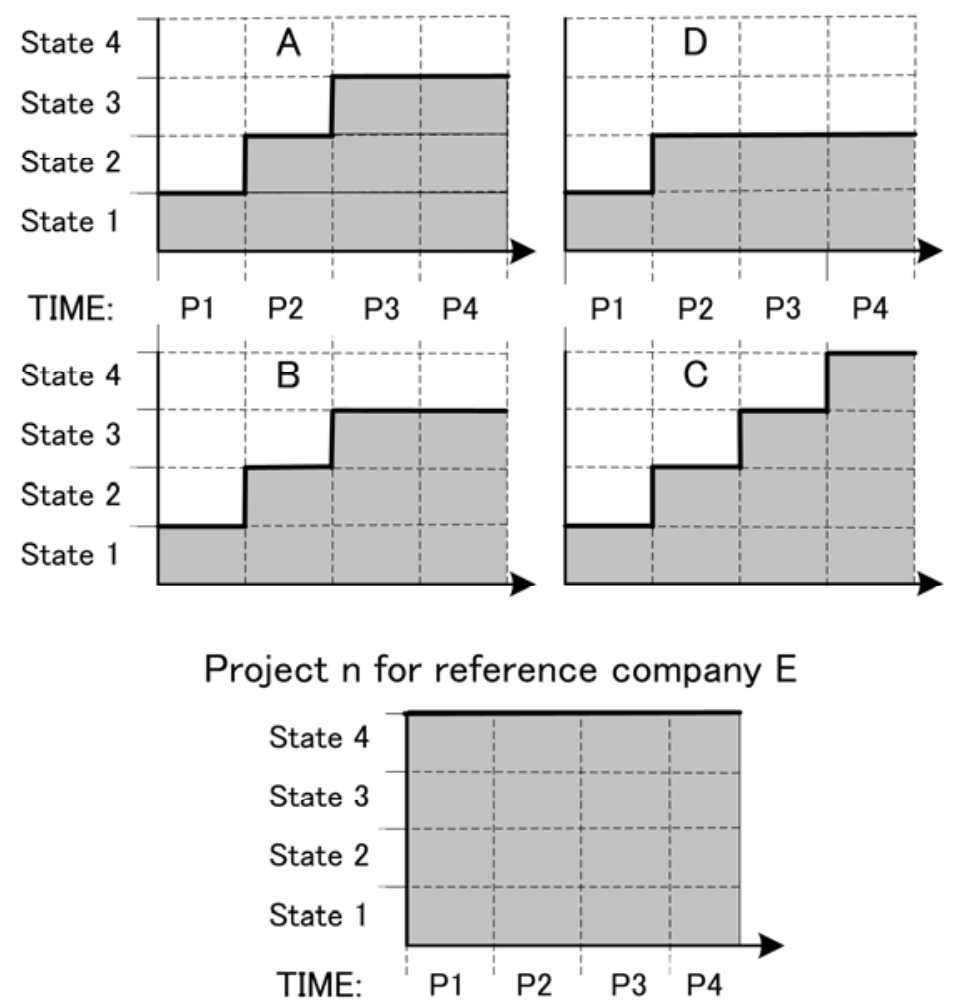

Fig. 3. Simplified schematic of tool adoption states reached by case study ventures

Towards the end of its first project, venture A was comfortably operating in the first three states, but because of its very small size in terms of number of employees, did not perceive a trigger for formal resource or portfolio management during the life of its maiden project. The team adopted tools of this nature later. Venture B's core development team also remained small during the course of the first project and they showed only limited adoption of process-oriented tools (state three). They did not progress to project or portfolio review activities or begin to adopt tools in support of resource management, and hence did not reach tool adoption state four. Because of the connection with its parent company, the team in venture $\mathrm{C}$ had a mix of experienced developers from the parent company and new inexperienced members. Peer pressure from the experienced members resulted in more rapid learning than in ventures $\mathrm{A}, \mathrm{B}$, and $\mathrm{D}$, which led to prompt progression through all four tool adoption states during their first project. Venture D also had a relatively large core development team, but the company grew fast to accommodate in-house volume production, and developed functional silos. Although the development team encountered the efficiency drivers associated with state three, staff inexperience and obstacles related to management structure and infrastructure prevented them from adopting tools in response.

In contrast to all four of the new ventures we studied, the established firm E did not progress through the four learning states during the course of the project, but in effect operated at all four levels from the beginning. Instead of adopting new classes of tool in response to external triggers, the team in this firm had existing institutional motivation to adopt the entire spectrum of tools without inherent limitation as to innovation stage. Another crucial difference from the four new venture teams was that all members had significant experience of similar projects within the company. However, as we note above, its institutionalised approach might still benefit from a 'renewal' stage or state (which lies outside the scope of this paper).

\section{Discussion}

Having proposed a model of tool adoption states within the start-up period of a new venture, we can also consider how the differences between our case study firms relate to tool adoption behaviour. We summarised the main firm characteristics in Table 3. All of the new venture teams started at the lowest tool adoption state in our hierarchy, but progression through higher learning states varied between ventures. Venture ownership was one factor that made a clear difference to this progression. In Venture C, the spinoff company, the experienced core of developers from the parent company acted as effective mentors for the team, and hence drove prompt progression through all four states. This experienced core was absent from the independent ventures A, B and D. 
Other than this 'experienced core' effect, larger team size did not connote a higher learning state or faster progression in terms of tool adoption. Indeed, it acted to inhibit progression in the case of Venture D. This had a large, newly-formed and fragmented team that had inadequate and unsupportive management structures and organisational processes. As a result, it lacked the absorptive capacity (Phelps et al., 2007) to progress through the learning states, despite individual team members perceiving unfulfilled needs. In contrast, the small but cohesive teams in Ventures A and B were able to progress through problem solving and efficiency tool adoption states, although not through to a 'big picture' or portfolio view. Our observations of Venture D support those of Clarysse and Morray (2004) that start-up teams larger than four persons are in practice very difficult to run, particularly if they rely on hired-in specialists to make up their expertise.

The other main driver of progression through the learning states that we saw in our new venture cases was external pressure, which was present in all cases. We did not perceive any differences according to whether the products were for consumer or industrial use or what proportion of sales was for export. Some additional demographic characteristics of firms might also influence tool adoption, but lie outside the scope of our study. For example, we only studied the maiden projects of young ventures, with one large established firm for comparison; we also limited our study to hardware-based high-technology projects in one geographic region.

The hierarchy of tool adoption states that we develop in this paper relates to existing theory by integrating the dominant problem concept outlined by Kazanjian (1988) with the concepts of tipping points and absorptive capacity from the Phelps et al. (2007) framework. This partially fulfils the Phelps et al. (2007) suggestion to develop theory by detailing the contingencies in which tipping points are reached and resolved. Our data and subsequent hierarchy of tool adoption states does exactly this in respect of types of innovation tool. The tipping points in this case are the new sets of problems teams encounter at each product innovation stage and their resolution depends on the absorptive capacity of the team. In terms of the Levie and Lichtenstein (2010) dynamic states model, our hierarchy occurs wholly within the start-up period and explains how firms' product innovation systems incrementally adapt to evolving conditions.

The contextual data we obtained in our case study firms, the personal involvement of the participants, and the variety of our cases give us confidence that the concept of a hierarchy of tool adoption states is likely to have wide applicability across new ventures. Although the actual tools adopted, and more importantly the manner of their adoption, will vary from one firm to another, we believe that most new ventures will progress through learning states with associated areas of tool focus. As firms become more established, they will reach the boundary condition for this model, beyond which the learning states in our model no longer apply. Instead, these established ventures will operate as our Company E, at all levels from the beginning of each new project.

\section{Practical Implications}

An important aspect of the above discussion is the performance outcomes that result in firms that progress in timely fashion or otherwise through the hierarchy of tool adoption states. Although our data do not specifically include a performance measure, we discuss in the literature review the existing evidence for a relationship between innovation tool adoption and performance. This would imply that new ventures should operate in all four states from the outset of their maiden project just as the established Company $\mathrm{E}$ did for the project we studied. In contrast, our cases suggest good rational reasons why none of the four new ventures acted in this way. At earlier stages in their maiden projects, the teams already found their time, resources and expertise fully stretched by the tasks they had to complete, and hence had to prioritise their adoption of product innovation tools and practices.

If advising new venture teams on innovation tool adoption, we would therefore not advocate that they should accelerate through the tool adoption states ahead of the pattern we gleaned from the case studies. Instead, developers and managers in such ventures should seek to move up the tool adoption hierarchy in timely fashion as the venture becomes established. They should do this by ensuring that their teams and organisational structures support a learning process and hence have the absorptive capacity to respond quickly to new dominant problems as they arise. Ventures that remain at the initial states in the hierarchy will likely fail to take off. In contrast to new ventures, teams in established firms are able to reap the benefits offered by all four tool adoption states without having to go through a re-learning process for each new project.

\section{Conclusions}

The product innovation literature points to efficiency and effectiveness as the main motivators for practitioners to adopt and use tools. However, our existing knowledge of these factors is not specific to technology based new ventures and does not address the needs, motivations and behaviours of product innovation practitioners in such firms. In this paper, therefore, we studied these factors in four cases of technology-based new ventures. We 
encapsulate the findings from these cases in a hierarchy of learning states for tool adoption, which applies the model of states and tipping points outlined by Phelps et al. (2007) to the adoption of innovation support tools. This hierarchy explains how users' problem focus evolves over time, starting with effectiveness, later adding problem solving and efficiency, and eventually including a big-picture focus on the productive use of resources. These dominant problems drive practitioners to adopt tools with a corresponding focus, provided that they have the capacity to do so.

Our cases show that when product innovation teams do not progress in timely fashion through this natural upwards progression in tool adoption, this results in costly mistakes and wasted time. The experienced team we studied in a well-established firm avoided unnecessary waste of this kind as they were able to operate effectively and efficiently within all four states from the beginning of their project. The literature tells us that this improves their performance. In contrast, our findings suggest that ab initio progression into all four states is not practical for new ventures, as their time, resources and expertise is already fully stretched. Hence, by codifying the tool-adoption development states in such ventures, we provide a framework to help new venture teams move to adopting new classes of innovation tool in timely fashion. 


\section{References}

Adams, M (2004). The 2004 PDMA Comparative Performance Assessment Study: Initial Findings (PDF document): The Product Development \& Management Association Foundation.

Almus, M, and EA Nerlinger (1999). Growth of new technology-based firms: Which factors matter? Small Business Economics, 13(2), 141-154.

Brady, T, H Rush, M Hobday, A Davies, D Probert, and S Banerjee (1997). Tools for technology management: An academic perspective. Technovation, 17(8), 417-426.

Brown, D (1997). Innovation Management Tools: A Review of Selected Methodologies. European Commission, EUR 17018.

Chai, KH, and Y Xin (2006). The Application of New Product Development Tools in Industry: The Case of Singapore. IEEE Transactions on Engineering Management, 53(4), 543-554.

Clarysse, B, and N Moray (2004). A process study of entrepreneurial team formation: the case of a researchbased spin-off. Journal of Business Venturing, 19(1), 55-79.

Cohen, WM, and DA Levinthal (1990). Absorptive capacity: a new perspective on learning and innovation. Administrative Science Quarterly, 35, 128-152.

Cooper, RG (1994). Third-generation new product process. Journal of Product Innovation Management, 11(1), 3-14.

Cooper, RG, and SJ Edgett (2008). Maximizing Productivity in Product Innovation. Research Technology Management, 51(2), 47-58.

Cooper, RG, and EJ Kleinschmidt (1986). An Investigation into the New Product Process: Steps, Deficiencies, and Impact. The Journal of Product Innovation Management, 3(2), 71-85.

de Waal, GA, and P Knott (2010). An Integrative Framework for Studying New Product Development Activity and Tools. Human Systems Management, 29(4), 253-264.

Dodge, HR, and JE Robbins (1992). An empirical investigation of the organizational life cycle model for small business development and survival. Journal of Small Business Management, 30(1), 27-37.

Eisenhardt, KM (1989). Building theories from case study research. Academy of Management Review, 14(4), 532-550.

Farrukh, CJP, R Phaal, and DR Probert (1999). Tools for Technology Management: Dimensions and Issues. Paper presented at the Portland International Conference on Management of Engineering and Technology (PICMET 99), Portland, 25-29th June 1999.

Gladwell, M (2000). The tipping point: How little things can make a big difference. Boston: Little Brown.

Hanks, SH, CJ Watson, E Jansen, and GN Chandler (1993a). Tightening the Life-Cycle Construct: A Taxonomic Study of Growth Stage Configurations in High-Technology Organizations. Entrepreneurship Theory and Practice, Winter, 5-29.

Hanks, SH, CJ Watson, E Jansen, and GN Chandler (1993b). Tightening the life-cycle construct: A taxonomic study of growth stage configurations in high-technology organizations. Entrepreneurship Theory and Practice, 18(2), 5-29.

Hansen, EL, and BJ Bird (1997). The Stages Model of High-Tech Venture Founding: Tried but True? Entrepreneurship Theory and Practice, Winter, 111-122.

Hidalgo, A, and J Albors (2008). Innovation management techniques and tools: a review from theory and practice. $R$ \& D Management, 38(2), 113-127.

Kazanjian, RK (1988). Relation Of Dominant Problems To Stages Of Growth In Technology-based New Ventures. Academy of Management Journal, 31(2), 257-278.

Kazanjian, RK, and R Drazin (1990). A State-Contingent Model of Design and Growth for Technology Based New Ventures. Journal of Business Venturing, 5(3), 137-150.

Knott, P (2008). Strategy tools: who really uses them? The Journal of Business Strategy, 29(5), $26-31$.

Koen, PA, GM Ajamian, S Boyce, A Clamen, E Fisher, S Fountoulakis, et al. (2002). Fuzzy Front End: Effective Methods, Tools, and Techniques. In P. Belliveau, A. Griffin and S. Somermeyer (Eds.), The PDMA ToolBook 1 for New Product Development (pp. 5-35). New York: John Wiley \& Sons, Inc.

Ledwith, A, and M O'Dwyer (2008). Product launch, product advantage and market orientation in SMEs. Journal of Small Business and Enterprise Development, 15(1), 96-110.

Levie, J, and BB Lichtenstein (2010). A Terminal Assessment of Stages Theory: Introducing a Dynamic States Approach to Entrepreneurship. Entrepreneurship Theory and Practice, 34(2), 317-350.

Mahajan, V, and J Wind (1992). New Product Models: Practice, Shortcomings and Desired Improvements. The Journal of Product Innovation Management, 9(2), 128-139.

Maslow, AH (1943). A Theory of Human Motivation. Psychological Review, 50, 370-396.

Maylor, H (2001). Assessing the relationship between practice changes and process improvement in new product development. Omega, The International Journal of Management Science, 29(1), 85-96.

McGuire, E (1973). Evaluating New Product Proposals (No. 604). New York: Conference Board. 
McQuater, RE, CH Scurr, BG Dale, and PG Hillman (1995). Using quality tools and techniques successfully. The TQM Magazine, 7(6), 37-42.

Nijssen, EJ, and RT Frambach (2000). Determinants of the adoption of new product development tools by industrial firms. Industrial Marketing Management, 29(2), 121-131.

Nijssen, EJ, and KFM Lieshout (1995). Awareness, use and effectiveness of models and methods for new product development. European Journal of Marketing, 29(10), 27-44.

Perry, C (1998). Processes of a case study methodology for post graduate research in marketing. European Journal of Marketing, 32(9/10), 785-802.

Phelps, R, R Adams, and J Bessant (2007). Life cycles of growing organizations: A review with implications for knowledge and learning. International Journal of Management Reviews, 9(1), 1-30.

Rahim, RA, and MSN Baksh (2003). Case study method for new product development in engineer-to-order organizations. Work Study, 52(1), 25-36.

Rigby, DK (2001b). Management tools and techniques: A survey. California Management Review, 43(2), 139160.

Schelker, T (1976). Problem Solving Methods in the New Product Development Process (in German). Bern: Verlag Paul Haupt.

Song, XM, WE Souder, and B Dyer (1997). A causal model of the impact of skills, and design sensitivity on new product performance. Journal of Product Innovation Management, 14(2), 88-101.

Thia, CW, KH Chai, J Bauly, and Y Xin (2005). An exploratory study of the use of quality tools and techniques in product development. The TQM Magazine, 17(5), 406-424.

Thomke, SH (2006). Capturing the Real Value of Innovation Tools. MIT Sloan Management Review, 47(2), 2432.

Tidd, J, J Bessant, and K Pavitt (2005). Managing Innovation - Integrating technological, market and organizational change (3rd ed.). Australia: John Wiley and Sons.

Tidd, J, J Bessant, and K Pavitt (2008a). Innovation Management Toolbox. Retrieved 2008 from http://www.wiley.co.uk/wileychi/innovate/website

Tidd, J, J Bessant, and K Pavitt (2008b). Managing Innovation. Retrieved 2008 from http://www.managinginnovation.com/innovation/cda/toolbox.php

Tidd, J, and K Bodley (2002). The influence of project novelty on the new product development process. $R \& D$ Management, 32(2), 127-138.

Yeh, T, C Yang, and F Pai (2008). Performance improvement in new product development with effective tools and techniques adoption for high-tech industries. [Online]. Quality and Quantity, 44(1), 131-152. 
Appendix 1 Data summary ordered by product innovation stage

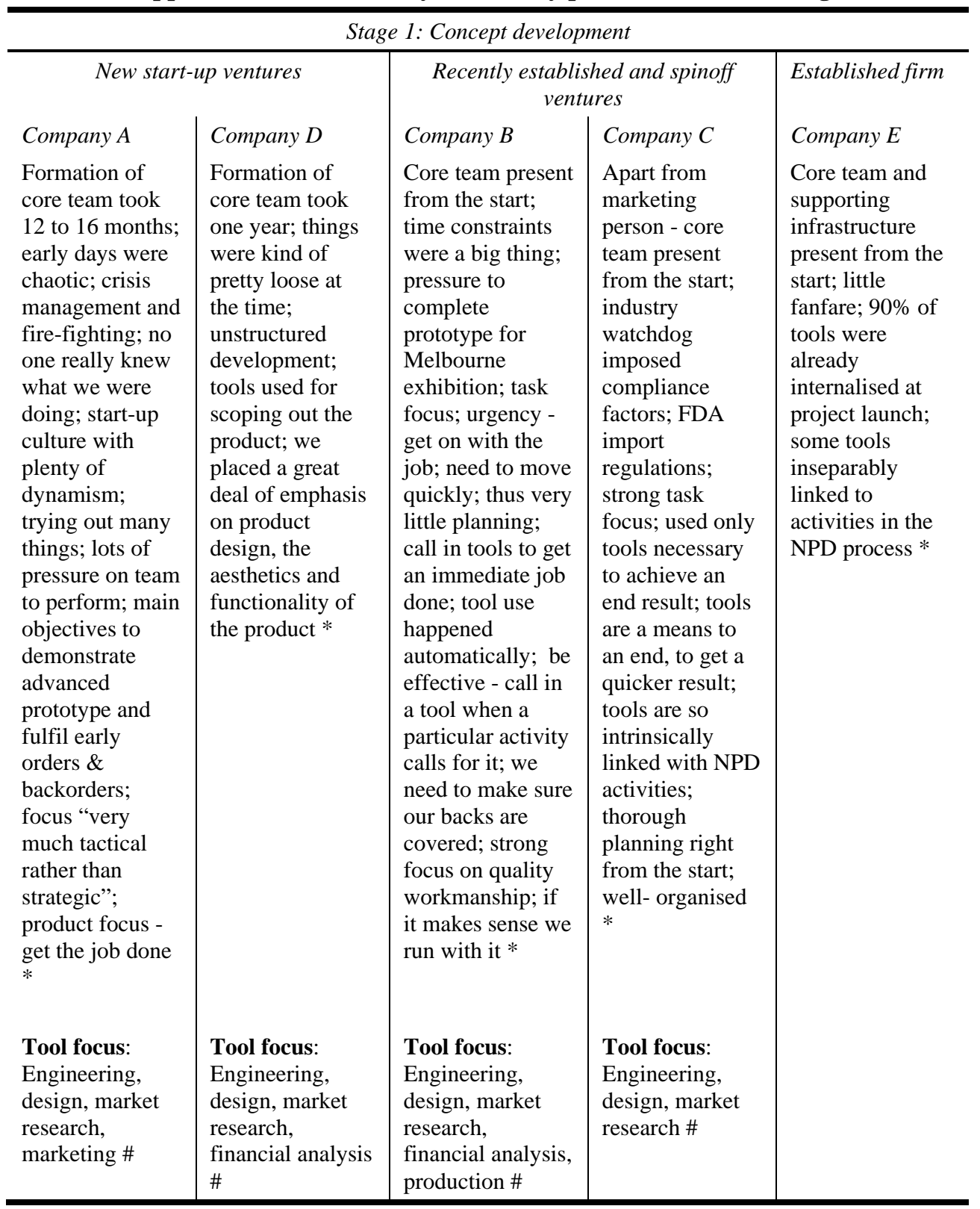

* Coded extracts that emerged from analysis

\# Classification based on authors' interpretation of data 
Appendix 1(continued)

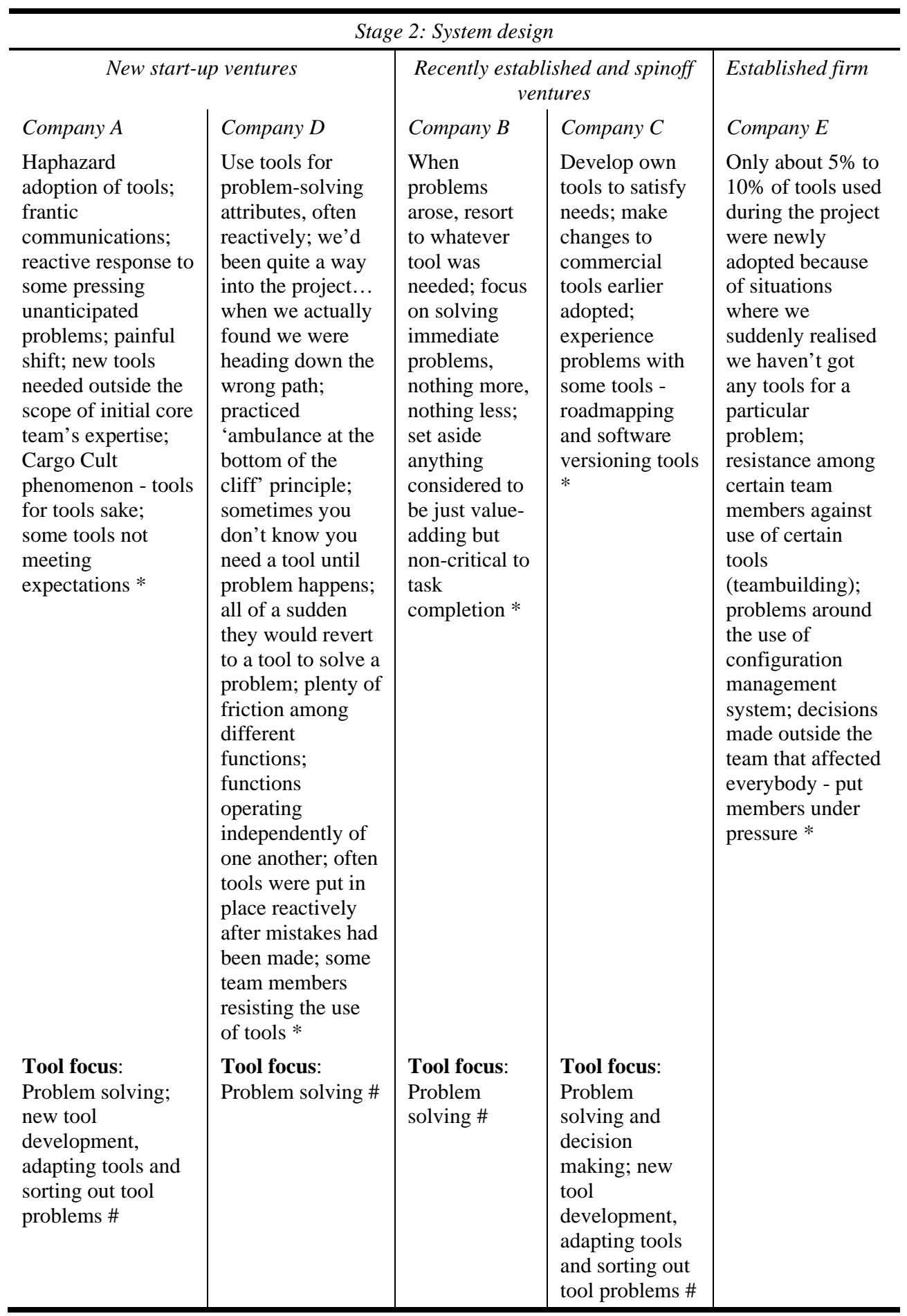

* Coded extracts that emerged from analysis

\# Classification based on authors' interpretation of data 
Appendix 1 (continued)

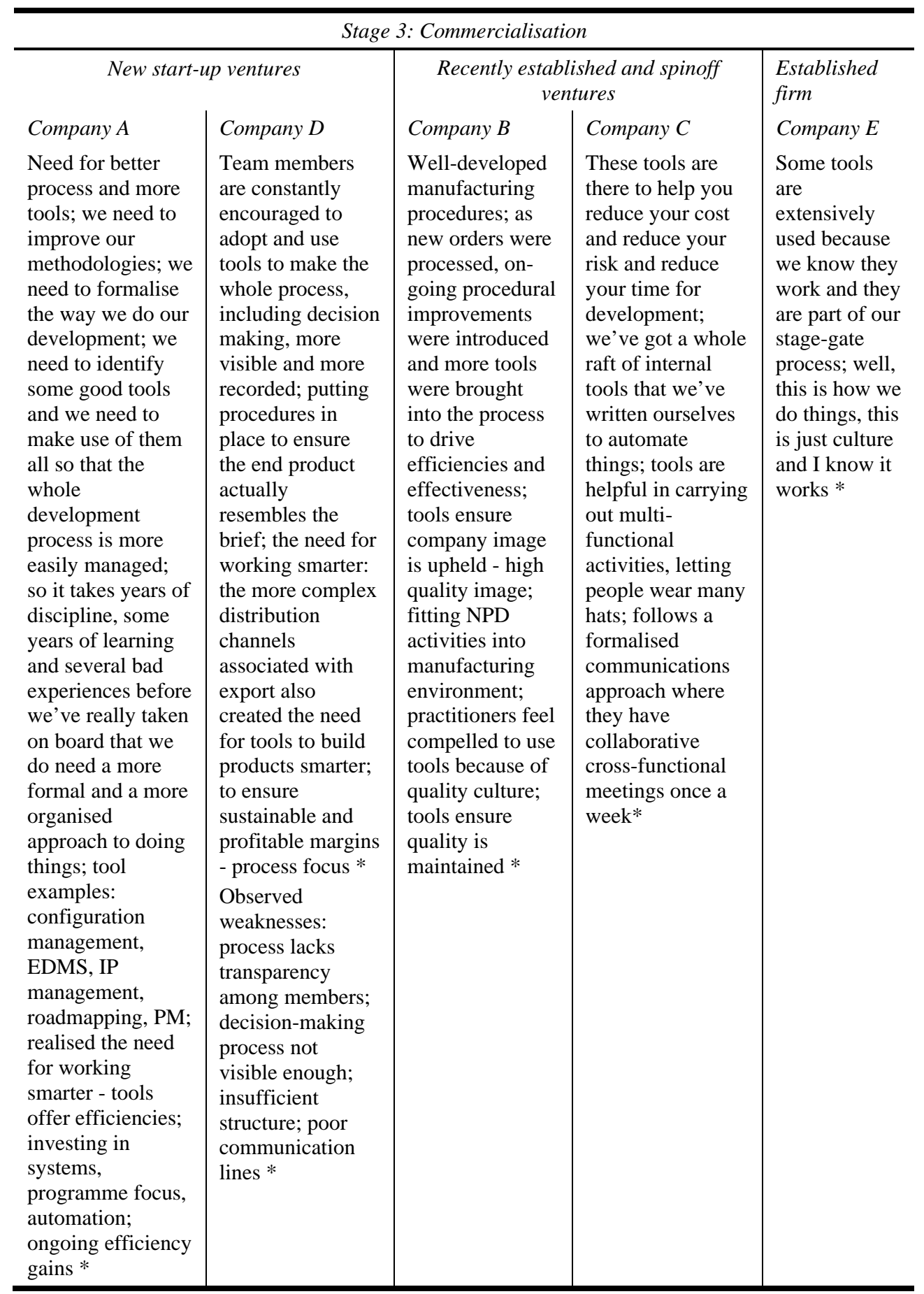

* Coded extracts that emerged from analysis 
Appendix 1 (continued)

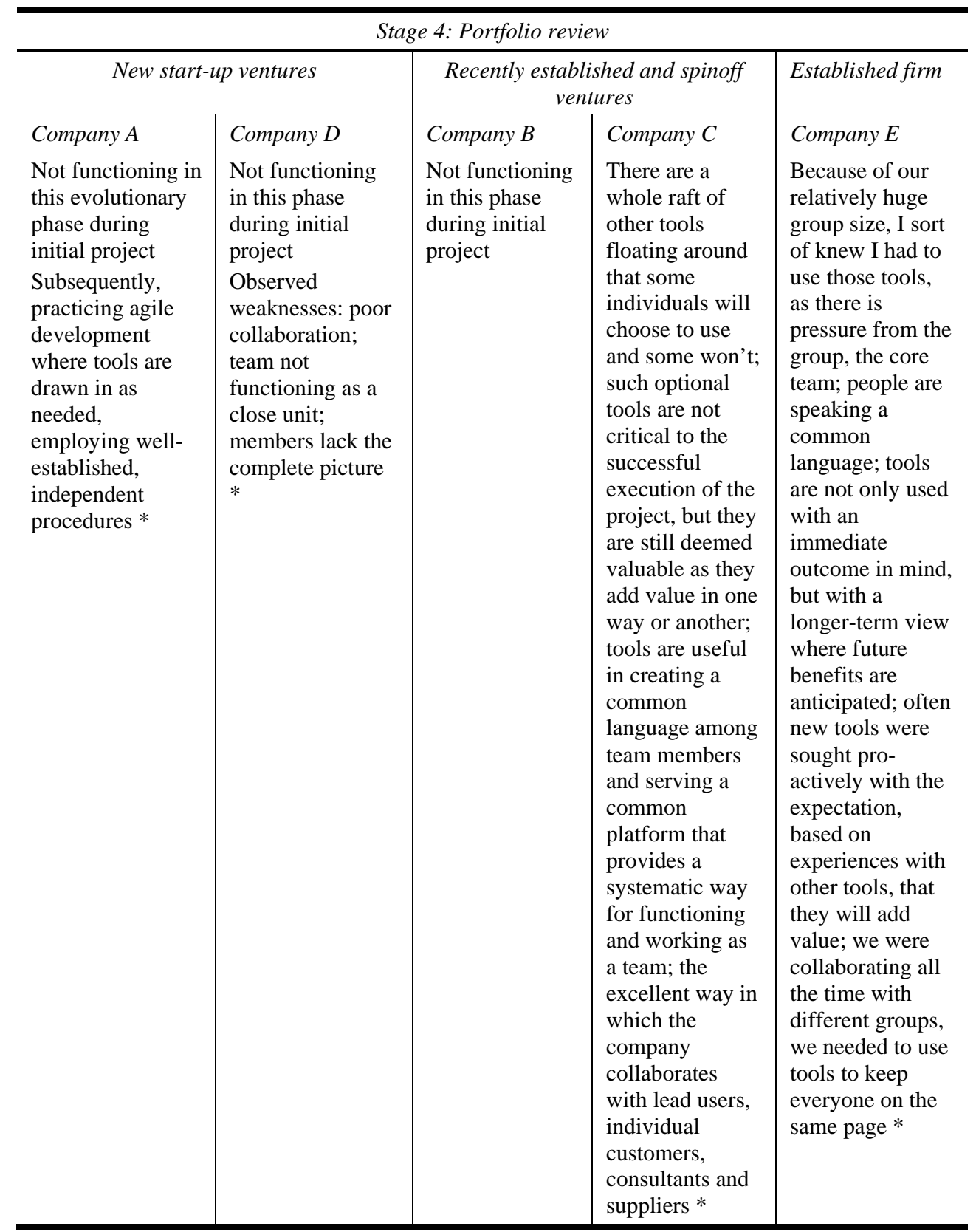

* Coded extracts that emerged from analysis 